\title{
DIGITAL TENSION: A COMPARISON BETWEEN DEMOCRACIES AND AUTHORITARIAN REGIMES
}

\author{
A. Bajpai \\ Agra College, Dr BRA University, \\ Mahatma Gandhi Rd, Mantola, Agra, Uttar Pradesh 282001, India
}

\begin{abstract}
There is no looking back from the ever-increasing digitalization of political processes and administration. This is a global phenomenon, but it has different impacts in democratic and authoritarian regimes. This theoretical paper seeks to explain this difference using the concept of digital tension. Digital tension refers to incompatibility among the different components of digital technology, which gives rise to incongruence and even conflict between different outcomes of use of digital technology to political processes. Digital technology promotes openness, transparency, and decentralized use, but it also facilitates centralization of monitoring and control. The outcomes of openness, decentralization, and transparency in actual practice go against the centralizing tendencies inherent in the same technology. In political discourse we say that digital technology empowers ordinary citizens, but we can also assert that it equally empowers rulers in a political regime. However, the interests of the rulers and the ruled are not the same even in democratic regimes. Since governing authorities are more resourceful, they are likely to use digital technology to enhance their power. This tendency is found in both democratic and authoritarian regimes. In democratic regimes, the ruling regime may use digital technology not only to centralized monitoring and control, but also for greater surveillance of opponents and critics. However, digital tension is well managed in authoritarian regimes, and hence the empowerment of rulers through digital technology is more pronounced. Thus, digital technology for centralized monitoring, supervision, and control is a boon for authoritarian regimes. This paper is divided onto four parts: Part one deals with theoretical issues related to digital technology and digital tension, Part two analyzes the role of digital technology in democratic regimes, Part three explains the use of this technology in authoritarian regimes, and Part four compares democratic and authoritarian regimes with respect to the use of digital technology and lists conclusions of this study.
\end{abstract}

Keywords: digital tensions, democratic regimes, authoritarian regimes, centralization of control, digital tension management, ruler empowerment.

\section{PART ONE}

The digital technology has revolutionary impact on human life. No Aspect of human life has escaped the influence of modern digital technology. It has deeply affected our way of life-how we perceive, think and do things. The digital technology has immense capabilities: storage of large amount of information and data, very large coverage in the exchange of this information, and high speed of data exchange among people communities and institutions. These abilities of digital technologies have been harnessed in various fields with various tool sand sub-technologies.

(c) St. Petersburg State University, 2021 
In the similar fashion, the use of digital technologies is increasing in political process and state activities. The notion of E-Governance encapsulates all dimensions of use of digital technology in the administration and governance: storage of huge information; collection and processing of huge data for policy-making, feedback, monitoring in real time basis, and participation of people in policy implementation, delivering public services with ease; faster and open redressal of public grievances; ensuring transparency, accountability in administration; and coordination at different levels etc. In brief, digital technologies are being used in the entire cycle of governance and administration. Besides governance, the use of digital technologies is equally pronounced in political process of modern democracies like canvassing by political parties, management of all phases of elections and soon.

\section{What is digital tension?}

Digital tension arises due to the dual nature of digital technology which has produced contradictory outcomes for the rulers and ruled. Digital tension refers to the incompatibility among the different components of digital technology. It gives rise to incongruence and even conflict between the different outcomes of the application of the digital technology on the political process. The digital technology promotes openness, transparency and decentralized use on the one hand, but it also facilitates centralization of monitoring and control on the other. The outcomes of openness, decentralization and transparency in actual practice militate against the centralizing tendencies inherent in the same technology. This conflict brought about by the digital technology is known as 'digital tension'.

The following features of Digital Technology underline the inherent tensions in the technology itself:

1. Openness and participation vs control and monitoring: It promotes openness when accessed by people, but it promotes the monitoring and control of the same people when used by political regimes for that purpose.

2. Empowerment of citizens vs empowerment of political regimes: Digital technology is said to empower the citizens by giving them access to information about the functioning of the government, but it also equally empowers the political regime by allowing the possession and use of citizens' private data and preferences.

3. Decentralization of political process vs increasing centralization: The digital technology allows the decentralization of decision-making process and political participation, but its use by political regimes promotes more centralization and control of the same process.

4. Equality in access vs inequality in access: The digital technology has the potential to bridge the gap between the different segments of citizens but, the digital divide deprives large section of citizens from the fruits of digital technology leading to widening of inequalities on the one hand and development of new oligarchies, which works in tandem with political regimes of all colour and shapes. 
In brief, the digital technology is like a double edged weapon. Its outcome depends upon the fact that who uses it and for what purpose? The digital technology promotes both openness and control; empowerment of citizens and political regimes both; Centralization and Decentralization of political and administrative processes; and finally the equality and inequality both in the access and use of digital technology.

In all political regimes there is a lesser or more incongruence of interests between the rulers and ruled. This incongruence is more pronounced in authoritarian regimes as the rulers are not even periodically accountable to the ruled even during elections. But such incongruence is not totally absent in democratic regimes. Hence the rulers in the democratic regimes are also prone to use digital technology for gaining power in the democratic process; and greater empowerment and centralization of power in their hands, as and when they are in ruling positions. Also, the ruling class is always better equipped to harness the benefits of new technology than the common man in both the democratic and authoritarian regimes. The point to analyze is as how the digital technology makes more powerful to those who are already powerful and more vulnerable to those who are already vulnerable?

\section{PART TWO}

\section{DIGITAL TENSION AND DEMOCRATIC REGIMES}

Whenever any new technology comes human mind is more prone to highlight its benefits and ignore its challenges and threats. This is what happened with the use of digital technology in the governance, administration and political process.

\section{Digital technology: Positive use}

By positive use we mean those uses of digital technology in such manner and such areas which strengthen democratic process and institutions and advance the goals of democracy. Some of the positive impacts of uses of digital technology in the democratic regimes are:

1. Creating political awareness among citizens;

2. Popular involvement in the formulation and implementation of public policies;

3. Helps organizing popular opposition;

4. Effective redressal of public grievances;

5. Improves delivery of public services;

6. Increases accountability of public authorities;

7. Facilitates political process.

While discussing the role of digital technology in modern democracies, Limon (2020) remarks, 'Digital technology allows citizens to scrutinize the actions and decisions of government officials (e. g. in the context of corruption) to degrees that would have been unimaginable only a decade ago. It also makes it easier for citizens to connect with candidates and their elected representatives, while social media and online campaigns have helped strengthen the civil and political participation 
of millions living in democratic societies, especially young people and marginalized groups'.

\section{Negative use of digital technology in democratic regimes}

The notion of digital tension postulates that the same technology may be used by democratic regimes in such a manner which produces negative outcomes and hence lead to the subversion of democratic process. Some of the major negative outcomes of digital technology for the democratic process are listed below:

1. Greater monitoring and surveillance of public activities: The digital technology enables the rulers even in the democratic regimes to collect information about their real and possible opponents and monitor their activities. This hampers the growth of healthy opposition which is the essence of functioning democracy. The present government of India (2021) faces the charge of misusing digital technology through a tool call Pegasus to collect information about those opposition leaders, journalists and writers who are opposed to the government. Many scholars [Mehta, 2021; Pegasus... 2021] have termed it as the threat to the Indian democracy.

2. Threat to privacy of citizens: While using digital technology for various public services, the government collects large amount of personal information from citizens, which remains in the possession of the government agencies. Such personal information may be misused by the government for different purposes. In 2021, the government of India has issued guidelines for the control of online social media, which not only infringes the right to privacy but also the freedom of speech [Explainer... 2021].The unrestrained and largely unexamined collection of personal data inhibits one's right to be left alone [Shahbaz, 2018].

3. Greater centralization of authority: The decentralization of administrative and political powers has been considered as the essential condition for the success of democracy by preventing the misuse of powers. But, the digital technology enables the rulers to centralize authority at the top by centralization functions of real time monitoring and control of various administrative and political activities and processes.

4. Misuse of digital technology in political process (elections): Free and fair elections are the pillar of the democratic process. There is increasing tendency to use digital technology in the elections and canvassing by political parties among voters. But the digital technology tools are suspect to be manipulated to rig the elections. India has adopted electronic voting machines for voting and counting of votes in elections. But many political parties and groups have expressed apprehension about their misuse by the ruling party [Electronic Voting Machine... 2019]. In addition, the political parties tend to misuse digital technology to spread false propaganda and hate speech. A noted scholar remarks, 'the negative impacts of (the misuse of) digital technology on peoples' right to choose their elected representatives in free and fair polls, and their right to receive accurate and honest information to help them make that choice, have - surprisingly - received far less attention. Until this situation 
is rectified - there is a real risk that digital technology will increasingly be used to foment doubt and mistrust in democratic institutions and processes' [Limon, 2020].

Even the most democratic regimes like the Britain and US have not escaped the misuse of digital technology in the election process. There are repeated allegation that during the Brexit vote in 2016, the Vote Leave (the official Leave campaign) had spent $£ 3.9 \mathrm{~m}$, more than half its official campaign budget, paying for the services of Aggregate IQ, which in collaboration with another ICT firm Cambridge Analytica 'harvested' data from Facebook profiles of voters, and identified 'emotional triggers' for each individual voter, and then ran a nationwide social media campaign 'micro targeting' those voters with messages tailored to play on their known fears or prejudices to vote in favour of leaving EU.

The case of the US Presidential election (2016) and allegation of Russia managing and influencing elections is not less curious. The US Senate released in August, 2020 the final report on its investigation into Russian interference in American elections using social media. The report criticized major US technology companies, including Facebook, Twitter, YouTube and Google, for helping spread misinformation during the 2016 Presidential polls. The Senate Committee's reports mentions that the interference was 'overtly' and 'almost invariably' supportive of Donald Trump to the detriment of Hillary Clinton's campaign. The report also gave examples of how misinformation can spread. Days after the 2016 election, a falsified media account of President Trump having won the popular vote briefly ranked higher on Google than stories that accurately reflected the popular vote, which was won by Ms Clinton. These findings are in tune with the investigation of the US intelligence community and former Special Counsel Robert Mueller [Limon, 2020].

\section{Democracy and digital technology: Seven concerns}

The Pew Research Centre and Elon University conducted a survey among technology experts to assess the future effects of people's use of technology on democracy by the year 2030. As much as 49 percent respondents said that digital technology will weaken democracy, while 33 percent indicated it will strengthen democracy and 18 percent found no significant change. The survey identified seven major concerns for democratic regimes due to the use of digital technology [Anderson and Rainie, 2020]: Empowering the Powerful, Diminishing the Governed, Exploiting Digital Illiteracy, Waging Info-Wars, Sowing Confusion, Weakening Journalism, and Responding too Slowly.

The debate on the misuse of digital technology in the democratic process is catching global attentions gradually. Piccone (2016) has identified three challenges for democratic government posed by the digital technology: Protecting fair elections, protecting fundamental rights online, and multi-stakeholder approaches to internet governance. He further remarks, 'The progressive digitization of nearly all facets of society and the inherent trans-border nature of the internet raise a host of difficult problems when public and private information online is subject to manipulation, hacking, and theft'. 


\section{PART THREE}

\section{DIGITAL TENSION AND AUTHORITARIAN REGIMES}

In fact, the beneficial use of the digital technology in the governance is nearly same in the authoritarian regimes as we have seen in the case of governance in democratic regimes. However, the negative use of digital technology is more pronounced in the authoritarian regimes. The authoritarian regimes make the effective use of digital technology for three fundamental objectives:

First, to ward off domestic populace and their groups from the external ideas and values which may be inimical to the value premises of established regime.

Second, the generate and sustain the support for the values and practices of the regime; and

Third, to monitor and control the activities of people and possible opponents, who are likely to oppose or challenge the established regime?

\section{Patters of use of digital technology}

In view of the above objectives, the authoritarian regimes, three patterns of use or misuse of digital technology are visible in such regimes:

\section{Effective control over digital media and tools}

The Authoritarian regimes suffer from the crisis of legitimacy and would like to perpetuate the values and norms of regimes to avoid such crisis in the long run. Hence they are in greater need of controlling any media including digital technology. The state control of digital technology to ward off external influences and its use for the regime propaganda are pervasive practices and strategies in the authoritarian regimes. This is known as 'Digital authoritarianism'. This found in all authoritarian and semi-authoritarian regimes.

Freedom House has conducted status of internet freedom in 65 countries in 2020. It has grouped countries into three categories: internet freedom, partial internet freedom and no internet freedom. Out of these, 19 countries have been recorded in the category of no internet freedom: Azerbaijan, Bahrain, China, Cuba, Egypt, Ethiopia, Iran, Kazakhstan, Myanmar, Pakistan, Russia, Rwanda, Saudi Arabia, Sudan, Turkey, UAE, Uzbekistan, Venezuela, and Vietnam. However, all of them cannot be termed as authoritarian regimes in equal measures [Countries, Internet Freedom, 2020]. These are either authoritarian or semi-authoritarian regimes.

The practices deployed for restricting internet freedom are: restricting the access to internet services, screening the contents of the internet, limited the content of the internet and permitting only state controlled domestic players as internet service providers. For example, China maintains control over all gateways to the global internet, which enables her to restrict the access to the content hosted outside the country. Informally this is known as 'Great Firewall' in China [Qin, 2020]. Also the government in China declares any internet content as subverting the CCP regime, or challenging the social, ethnic, religious, or economic policies of the government. Such content is not available to citizens [Governing the E-cosystem 2, 2020]. 


\section{Effective monitoring and surveillance of activities of people}

The authoritarian regimes live under the constant threat of popular opposition and uprising. Hence they need to monitor those groups and people who are likely to pose threat to the regime. For this the authoritarian regimes deploy digital technology tools like face re cognition tools, finger identification mechanism, and camera monitoring and surveillance of mobile and social media surveillance. China and North Korea, the typical examples of authoritarian regimes deploy such tools to monitor and control the target population. China has deployed such tools in extensive scale in the restive Xinjhiang province where Uighur minority community is demanding greater autonomy and human rights. In 2017, Chinese authorities identified more than 40,000 Uighurs for internment by monitoring their use of the video and audio-sharing app Zapya [Ma, 2019].

\section{Centralization of authority through digital coordination and control}

The authoritarian regimes are very nature more prone to centralization of power and authority. The digital technology comes handy for rulers to coordinate, monitor and control the subordinate public agencies in real time basis. Thus, the digital techno logy further accelerates the tendency of centralization of authority in authoritarian regimes. In its extreme form the centralization of power takes the personalized form and in such cases the same technological tools are used for promotion of the image and position of the apex rulers. China's present leadership has deployed digital technology for such image building exercise of the rulers.

\section{CASES OF CHINA AND NORTH KOREA}

The three patters of the use of digital technology for the serving the fundamental interests of the authoritarian regimes can be illustrated some examples. For this purpose, we take the cases of China and North Korea as typical representative cases of authoritarian regimes.

China is an authoritative regime led by the CCP and its General Secretary. No Other political party is allowed to contest elections against the CCP. China has put in place an elaborate system of control and regulation over the use of digital technology, which works in the best interest of Communist regime. Freedom House [Freedom on the Internet... 2020] has carried out a detailed report of the use and con troll of digital technology in China. The report has concluded that the "conditions for internet users in China continued to deteriorate, confirming the country's status as the world's worst abuser of internet freedom for the sixth consecutive year'.

In recent years, China's authoritarian regime has tightened its control over the state bureaucracy, the media, religious groups, universities, businesses, and civil society associations. The CCP leader and state president, Xi Jinping, has consolidated personal power to a degree not seen in China for decades. As a result of intensifying controls, the online presence of independent civil society, human rights documentation, and prodemocracy viewpoints have declined, which is kind of self-censorship. Some of the specific uses of digital technology by the authoritarian regime of China are listed below: 
1. Under the law, the Chinese technology companies have been aiding government surveillance by transferring the user data to the government.

2. The government maintains control over China's gateways to the global internet, known as Great Firewall and restricts the outside content as per its requirement.

3. Only few external telecom companies are allowed to operate in China. Stateowned China Mobile, China Telecom and China Unicom dominate the mobile market.

4. CCP's Central Propaganda Department has exerted greater control over state regulation of the press, film, radio, and television industries in recent years.

5. China has strict rule to limit the internet contents which are declared subversive to the Communist regime or the government policies. Under the new online media guideline rules (01 March, 2020), the online content has three categories: encouraged positive content, discouraged negative content, and illegal content. Only positive content related to party doctrine is allowed on the internet.

6. There is growing censorship of popular and political platforms such as dating, video-sharing, live-streaming, and blockchain applications, leading to the reduced presence of social media in public life.

7. Direct surveillance of internet and mobile phone communications is pervasive and highly sophisticated. Residents of Xinjiang are subject to severely invasive surveillance tactics. In February 2019, security researcher Victor Gevers discovered and exposed a large database containing the personal information of 2.6 million people in Xinjiang. This data is used for further action against targeted individual [Freedom on the Internet, 2020].

While China has pervasive control mechanism on digital technology for its selective use in the interest of communist regime, it close ally North Korea is one step ahead in such control and use of digital technology for perpetuating hereditary regime for decades. North Korea has put in place various elaborate measures for such control like strict control on internet, modifying the mobile software for spying, monitoring people's visits to internet site through spyware, ban on external phone calls through split mobile system, death sentence on viewing porn content, ban on open wi fi networks, and linking radios with government frequencies etc. On the other hand, the regime never fails to glorify their achievements and justify their rule using the digital technology tools [Asher, 2016; Ghosh, 2019].

\section{PART FOUR}

\section{DIGITAL TENSION: COMPARISON BETWEEN THE DEMOCRATIC AND AUTHORITARIAN REGIMES}

If we carefully observe the differences in the mechanisms and compulsions of the democratic regimes on the one hand and authoritarian regimes on the other, we find that there are three reasons which prompt authoritarian regimes to more pervasive and systematic use of digital technology to serve the fundamental interests of the regime. 


\section{Legitimacy needs}

Unlike democratic regimes, the authoritarian regimes face the persistent problem of the legitimacy of the regime. In democratic regimes, the pressure of legitimacy is siphoned off periodically by free elections and intermittently freedom of expression available to citizens and other stakeholders. But in the authoritarian regimes such pressure of legitimacy is never siphoned off. Hence there is a greater need to isolate the citizens from the new ideal and values which threaten the legitimacy of regimes.

In fact, the digital technology, with global outreach and decentralized control is more disruptive to the legitimacy of the authoritarian regimes. Hence there is greater need for the strict control on the digital technology. But the same technology is very useful for regime propaganda due to its greater reach and speed. Hence it is systematically used for the regime propaganda. In either case the authoritarian regimes need the total control on the digital techno logy and its tools to serve the legitimacy needs of the regimes. On the other hand, the democratic regimes place their legitimacy concern $s$ in the public domain, which are addressed on the continuous basis.

\section{Absence of check and balances}

The democratic regimes deploy various checks and balance e in the use of political power like the separation of powers among different organs of the government, or decentralization of political power through federal scheme or other devices, which are approved and maintained by the Constitutional scheme. In addition the rule of law provides open and rational courses of political actions. In such situation the rulers do not have much scope of the misuse of any technology including the digital technology, even if they have greed for power.

But on the contrary, such balance of power is absent in the authoritarian regimes and rulersdo not have any external accountability and control. The ideology of regime brings each organs of the government under the control of ruling cliques. Thus, the authoritarian regimes enjoy great impunity to misuse the digital technology in their own interest.

\section{The greater tendency of centralization}

Unlike the democratic regimes, there is greater tendency of centralization in authoritarian regimes. Decentralization of authority is inherently against the authoritarianism. Thus, the pervasive misuse of digital technology is more pronounced in centralized power structures of authoritarian regimes. The centralization of authority becomes personalized around the apex leader. Thus, the digital technology is at the disposal of the whims and interests of the leaders. It may used to consolidate the authority of leaders which are at control of the regime.

In brief, the need and compulsions for the misuse of digital technology are more pressing in authoritarian regimes in comparison to democratic regimes, which can be understood by the amount of digital tensions which is more pronounced in authoritarian regimes. Thus, the notion of digital tension can be used as tool for comparing the impact of digital technology in various types of political regimes. 


\section{CONCLUSION}

The digital technology has come to stay in political domain. The digital technology due to its larger coverage and speed and versatile nature has deeper impact in the political process. But the digital technology is like a double edged weapon, which may be used in both ways: strengthening the democratic process as well as subverting it. This is the result of digital tension inherent in the digital technology. Both democratic and authoritarian regimes have harnessed the positive potential of digital technology for the efficiency in the governance. But side by side, both types of regimes have also used the negative potential of this technology to serve their narrow and partisan interests. However the misuse of digital technology in democratic regimes on the one hand and authoritarian regimes on the other is not same in terms of its extent and nature of use. Due to certain inherent factors like need for legitimacy, absence of check and balances and greater centralization, the authoritarian regime are more prone to use digital technology for their interests by its control and selective deployment. The digital technology, among other things, is a very effective tool for the regime perpetuation and legitimacy in the authoritarian regimes. The idea of digital tension comes into full play in authoritarian regimes.

\section{References}

Anderson J., Rainie L. Themes about the digital disruption of democracy in the next decade. Report, Pew Research Centre, 2020, 21 February. Available At: https://www.pewresearch.org/internet/2020/02/21/themes-about-the-digital-disruption-of-democracy-in-the-next-decade/ (accessed 24.09.2021).

Asher S. What the North Korean internet really looks like. BBC News, 2016, 21 September. Available at: https://www.bbc.com/news/world-asia-37426725 (accessed: 24.09.2021).

Governing the E-cosystem 2. China Law Translate, 2020, 1 March. Available at: https://www. chinalawtranslate.com/en/governing-the-e-cosystem-2/ (accessed: 24.09.2021).

Electronic Voting Machine and its history with India: Controversy over EVMs malfunctioning, rigging allegations are not new, Firstpost, 2019, 22 January. Available at: https://www.firstpost.com/ india/electronic-voting-machine-and-its-history-with-india-controversy-over-evms-malfunctioning-rigging-allegations-are-not-new-5939961.html (accessed: 24.09.2021).

Countries, Internet Freedom. Freedom House, 2020. Available at: https://freedomhouse.org/ countries/freedom-net/scores (accessed: 24.09.2021).

Freedom on the Internet, China, Overview. Freedom House, 2020. Available at: https://freedomhouse.org/country/china/freedom-net/2020 (accessed: 24.09.2021).

Ghosh S. 10 ways North Korea uses technology to keep its citizens in the dark about the outside world. Business Insider India, 2019, 29 December. Available at: https://www.businessinsider. in/tech/news/10-ways-north-korea-uses-technology-to-keep-its-citizens-in-the-dark-about-theoutside-world/articleshow/73016549.cms (accessed: 24.09.2021).

Limon M. Is digital technology rotting British and American democracy from the inside out. Universal Rights Group, 2020, 17 September. Available at: https://www.universal-rights.org/ in-focus-democracy/is-digital-technology-rotting-british-and-american-democracy-from-the-inside-out/ (accessed: 24.09.2021).

Ma A. China used a file-sharing app to round up 40,000 Uighur Muslims for prison camps, a startling insight into how it oppresses people via technology, Business Insider, 2019, November 25. Available at: https://www.businessinsider.com/china-uighurs-prison-camps-round-up-zapyaapp-2019-11 (accessed: 24.09.2021). 
Mehta P. B. What the Pegasus surveillance scandal means for the Indian democracy? The Indian Express, 2021, 21 July. Available at: https://indianexpress.com/article/opinion/columns/pegasus-surveillance-scandal-indian-democracy-7414271/ (accessed: 24.09.2021).

Piccone T. Democracy and Digital Technology. Sur, the international Journal of Human Rights, 2018, July. Available at: https://sur.conectas.org/en/democracy-and-digital-technology/ (accessed: 24.09.2021).

Qin Ch. Inkstone Explains: How China engineers an alternative internet for its people. Inkstone News, 2020, Jun 11. Available at: https://www.inkstonenews.com/tech/inkstone-explains-how-china-engineers-alternative-internet-its-people/article/3088426 (accessed: 24.09.2021).

Explainer: Why India's new rules for social media, news sites are anti-democratic, unconstitutional. Scroll.In, 2021, 27 February. Available at: https://scroll.in/article/988105/explainer-how-indias-new-digital-media-rules-are-anti-democratic-and-unconstitutional (accessed: 24.09.2021)

Shahbaz A. The Rise of Digital Authoritarianism. The Freedom on the Net 2018, Freedom House, 2018. Available at: https://freedomhouse.org/report/freedom-net/2018/rise-digital-authoritarianism (accessed: 24.09.2021).

Pegasus: Newspapers Say Allegations Strike at the Heart of Democracy, Demand Probe. The Wire, 2021, 19 July. Available at: https://thewire.in/media/pegasus-newspapers-say-allegations-of-surveillance-are-concerning-demand-accountability (accessed: 24.09.2021).

Arunoday Bajpai - Dr., Associate Professor and Head; arunodaybajpai@gmail.com

Received: November 14, 2021

Accepted: November 23, 2021

For citation: Bajpai A. Digital tension: A comparison between democracies and authoritarian regimes. Political Expertise: POLITEX, 2021, vol. 17, no. 4, pp. 330-340.

https://doi.org/10.21638/spbu23.2021.401 